\title{
Evolução das matrículas de educação especial na educação infantil, fundamental e médio entre os anos de 2009 a 2020 no Brasil
}

\author{
Evolution of enrollments in special education in kindergarten, elementary and high school between
} 2009 and 2020 in Brazil

Evolución de la matrícula en educación especial en jardín de infantes, primaria y secundaria entre 2009 y 2020 en Brasil

\begin{abstract}
Resumo
Discutir sobre a inclusão de alunos com deficiência em ambiente escolar implica em trazer à tona questões muito amplas, como: o pouco investimento no sistema educacional brasileiro; a falta de infraestrutura no tocante a recursos físicos para atender a todos os alunos, sejam eles especiais ou não; o preconceito; a discriminação; e, a falta de credibilidade que ainda impera em relação às pessoas diferentes, principalmente as que possuem algum tipo de deficiência. Essas pessoas são desrespeitadas e não são compreendidas como seres humanos com potencialidades e capazes de produzir como os demais cidadãos. Este artigo tem o objetivo de averiguar a evolução de matriculas de educação especial na educação infantil e nos ensinos fundamental e médio de 2009 a 2020 no Brasil. Foi feito uma abordagem qualitativa, valeu-se da pesquisa bibliográfica. Para o desenvolvimento deste estudo, foram utilizadas como fontes de coleta de dados do Censo escolar de 2020 divulgado pelo Instituto Nacional de Estudos e Pesquisas Educacionais Anísio Teixeira e Diretoria de Estatísticas Educacionais. Nos anos de 2009 até 2020, as matriculas de alunos especiais em classe comum seguiu uma reta crescente na educação básica, no ensino fundamental e médio. Esse crescimento está relacionado a implementação de políticas públicas de educação e formação adequada de professores. Estes dados mostra a importância de uma política pública séria que luta pela inclusão dos alunos com algum tipo de deficiência sejam colocados dentro de uma classe comum.
\end{abstract}

Palavras-chave: Inclusão; Classe comum; Censo escolar.

\begin{abstract}
Discussing the inclusion of students with disabilities in the school environment implies bringing up very broad issues, such as: little investment in the Brazilian educational system; the lack of infrastructure in terms of physical resources to serve all students, whether special or not; the prejudice; discrimination; and the lack of credibility that still prevails in relation to different people, especially those with some kind of disability. These people are disrespected and are not understood as human beings with potential and capable of producing like other citizens. This article aims to investigate the evolution of special education enrollments in early childhood education and primary and secondary education from 2009 to 2020 in Brazil. A qualitative approach was used, using bibliographical research. For the development of this study, the 2020 School Census published by the National Institute of Educational Studies and Research Anísio Teixeira and the Directorate of Educational Statistics were used as data collection sources. In the years 2009 to 2020 , the enrollment of special students in the common class followed a growing line in basic education, elementary and secondary education. This growth is related to the implementation of public education policies and adequate teacher training. These data show the importance of a serious public policy that fights for the inclusion of students with some type of disability to be placed within a common class.
\end{abstract}

Keywords: Inclusion; Common class; School censos.

\section{Resumen}

Hablar de la inclusión de estudiantes con discapacidad en el entorno escolar implica plantear temas muy amplios, como: poca inversión en el sistema educativo brasileño; la falta de infraestructura en cuanto a recursos físicos para atender a todos los estudiantes, sean especiales o no; el prejuicio; discriminación; y la falta de credibilidad que aún prevalece en relación a distintas personas, especialmente aquellas con algún tipo de discapacidad. Estas personas son irrespetadas y no son entendidas como seres humanos con potencial y capaces de producir como los demás ciudadanos. 
Este artículo tiene como objetivo investigar la evolución de la matrícula de educación especial en la educación infantil y la educación primaria y secundaria de 2009 a 2020 en Brasil. Se utilizó un enfoque cualitativo, utilizando investigación bibliográfica. Para el desarrollo de este estudio se utilizó como fuentes de recolección de datos el Censo Escolar 2020 publicado por el Instituto Nacional de Estudios e Investigaciones Educativas Anísio Teixeira y la Dirección de Estadísticas Educativas. En los años 2009 a 2020, la inscripción de estudiantes especiales en la clase común siguió una línea creciente en la educación básica, primaria y secundaria. Este crecimiento está relacionado con la implementación de políticas públicas de educación y una adecuada formación docente. Estos datos muestran la importancia de una política pública seria que luche por la inclusión de estudiantes con algún tipo de discapacidad para ubicarlos dentro de una clase común.

Palabras clave: IlaveInclusión; Clase común; Censo escolar.

\section{Introdução}

A discussão sobre a inserção de alunos com deficiência no ensino regular iniciou-se anos atrás. Leis (Brasil, 1989; Brasil, 1996) e Declarações (Brasil, 1994) foram elaboradas, nas últimas décadas, contribuindo para orientar o processo de inserção da pessoa com deficiência no ensino regular. A Constituição da República Federativa do Brasil de 1988 (Brasil, 1988) explicitou a responsabilidade do poder público em relação à pessoa com deficiência e conferiu ao Ministério Público atribuição para atuar em casos de discriminação. Essa Lei dispôs sobre o apoio às pessoas com deficiência, sua inserção social e outras providências. Portanto, tornou-se obrigatório a aceitação de alunos com deficiências na escola brasileira (Brasil, 1988).

Acreditava-se que as salas especiais - modelo de atendimento de educação especial em que o aluno com deficiência era colocado nas escolas comuns, frequentando uma classe específica para ele, com alunos que apresentavam as mesmas necessidades educacionais, professores especializados e recursos próprios, dependendo da deficiência - seriam a solução para inclusão. Porém, da maneira como foram implantadas, não produziram o resultado esperado, conforme estudos de Caiado (1993); Ferreira (1992); Santos (2002). A partir da década de 1990, alguns movimentos nacionais e internacionais defendem os ideais de uma escola inclusiva, em que todos os alunos, com ou sem deficiência, deveriam frequentar escolas e salas de ensino regular.

Educação Inclusiva divide opiniões, uns são adeptos da classe especial e outros adeptos da classe regular. Segundo Mendes (2008), essas são as duas correntes em que se desenvolveram estudos referentes à temática. Entretanto, para a autora, mais importante do que o local onde será desenvolvida é a qualidade da educação que será oferecida. Para tanto, um dos aspectos a ser considerado é a preparação e formação dos professores que deverão atuar de acordo com essa nova realidade.

Discutir sobre a inclusão de alunos com deficiência em ambiente escolar implica em trazer à tona questões muito amplas, como: o pouco investimento no sistema educacional brasileiro; a falta de infraestrutura no tocante a recursos físicos para atender a todos os alunos, sejam eles especiais ou não; o preconceito; a discriminação; e, a falta de credibilidade que ainda impera em relação às pessoas diferentes, principalmente as que possuem algum tipo de deficiência. Essas pessoas são desrespeitadas e não são compreendidas como seres humanos com potencialidades e capazes de produzir como os demais cidadãos (Leonardo et al., 2009; Penha et al., 2020).

As pessoas com deficiências têm capacidade e potencialidade,mas entende que, para estas poderem desenvolvê-las, devem ser-lhes oferecidas condições materiais e instrumentais adequadas. Não é a deficiência em si, no que tange ao seu aspecto biológico, que atua por si mesma, e sim, o conjunto de relações que o indivíduo estabelece com o outro e com a sociedade, por conta de tal deficiência. Com isso, deve-se oferecer a tais pessoas uma educação que lhes oportunize a apropriação da cultura histórica e socialmente construída, para melhores possibilidades de desenvolvimento (Vigotski, 1997).

Gotti (1998), a inclusão escolar significa um novo paradigma no marco conceitual e ideológico, o qual precisa envolver políticas, programas, serviços, à comunidade em geral, etc. Assim, conforme a autora, incluir implica ações que envolvam a luta pela conscientização do direito à cidadania, como pré-requisito fundamental para uma reflexão crítica em torno dos conhecimentos, informações e sentimentos em relação às pessoas com deficiência. 
Este artigo tem o objetivo de averiguar a evolução de matriculas de educação especial na educação infantil e nos ensinos fundamental e médio de 2009 a 2020 no Brasil. Na primeira seção, apresentam-se a metodologia empregada na busca pelas fontes e os dados. Na segunda seção, serão abordados e discutidos os resultados das investigações efetuadas pelas pesquisas examinadas e, na terceira, as considerações finais.

\section{Metodologia e Resultados}

De abordagem qualitativa, valeu-se da pesquisa bibliográfica, que, de acordo com Gil (2008), é uma técnica utilizada com grande frequência em estudos exploratórios ou descritivos, casos em que o objeto de estudo proposto é pouco estudado e implica um conjunto ordenado de procedimentos de busca de soluções, atento ao objeto de estudo. Para o desenvolvimento deste estudo, foram utilizadas como fontes de coleta de dados do Censo escolar de 2020 divulgado pelo Instituto Nacional de Estudos e Pesquisas Educacionais Anísio Teixeira e Diretoria de Estatísticas Educacionais.

Após levantamento, nos dados do Censo escolar de 2020 divulgado pelo Instituto Nacional de Estudos e Pesquisas Educacionais Anísio Teixeira e Diretoria de Estatísticas Educacionais, foi averiguado que nos anos de 2009 a 2020 teve uma evolução nas matrículas de alunos com deficiência na educação infantil em escolas com classes comuns, no entanto, matrículas em escolas com classes especiais ou inclusivas teve um decréscimo nas matrículas entre os anos de 2009 a 2020 (Gráfico 1). A evolução das matriculas de alunos com deficiências no ensino fundamental, seguiu a mesma tendência de evolução na educação infantil em escolas com classes comuns e em escolas com classes especiais ou inclusivas (Gráfico 2). Já no ensino médio, a quantidade de alunos matriculados em escolas com classes especiais ou inclusivas se manteve estáveis entre os anos de 2009 a 2020, mas as matriculas em classes comuns teve um salto de 78,80\% de 2009 para 2020, onde em 2009 tinha matriculado $13,41 \%$ de alunos no ensino médio com deficiência em classes comum, em 2020 teve um salto para 92,21\% de alunos matriculados no ensino fundamental com deficiência em classes comum (Gráfico 3).

Percentual de alunos de educação especial incluídos (classe comum) por etapa de ensino, segundo a unidade da federação - Brasil 2020 apresentado no gráfico 4, podemos averiguar que todas as unidades de federação apresentam um percentual acima de $60 \%$ de alunos com deficiência matriculados em classe comum. Só estado do Paraná que apresentou menor percentual de alunos com deficiência matriculados em classes comum.

Analisando, as matrículas na educação especial por tipo de deficiência, transtorno global do desenvolvimento ou altas habilidades/superdotação - Brasil 2020, a deficiência intelectual tem a maior representatividade, seguido do autismo, da deficiência física e da deficiência múltipla.

Figura 1 - Evolução das matrículas de educação especial na educação infantil, por local de atendimento - Brasil 2009 - 2020.

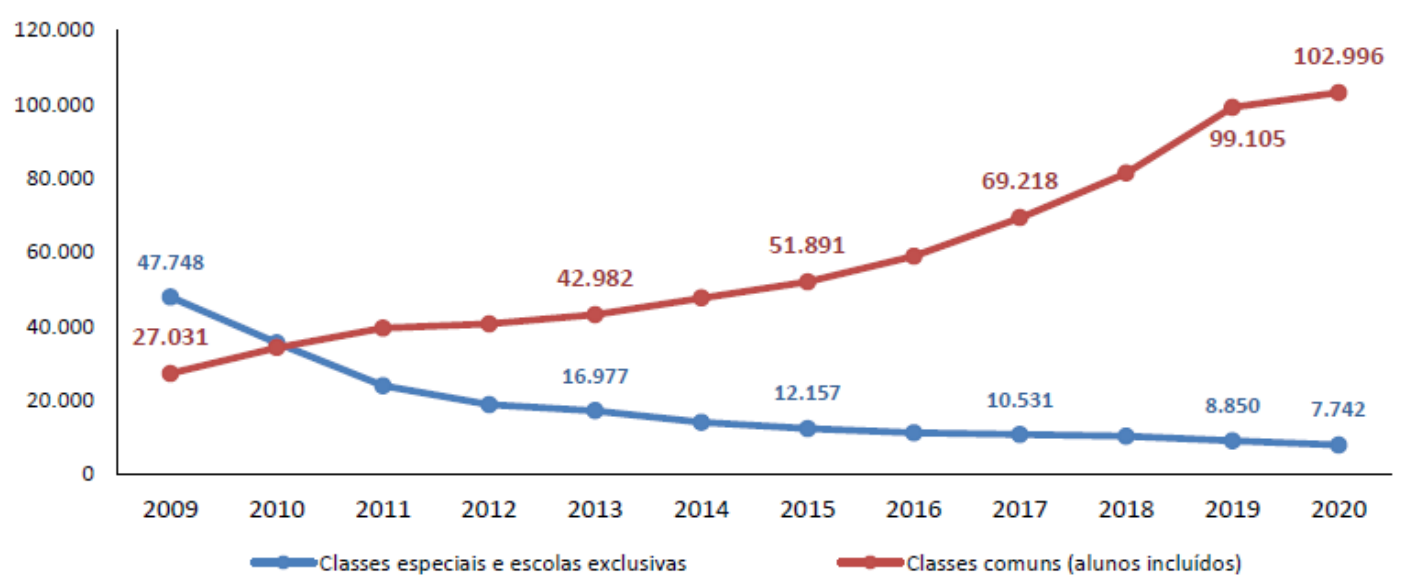

Fonte: Elaborado por Deed/Inep com base nos dados do Censo da Educação Básica 2020 (MEC, 2020). 
Figura 2 - Evolução das matrículas de educação especial no ensino fundamental, por local de atendimento - Brasil 2009 2020 .

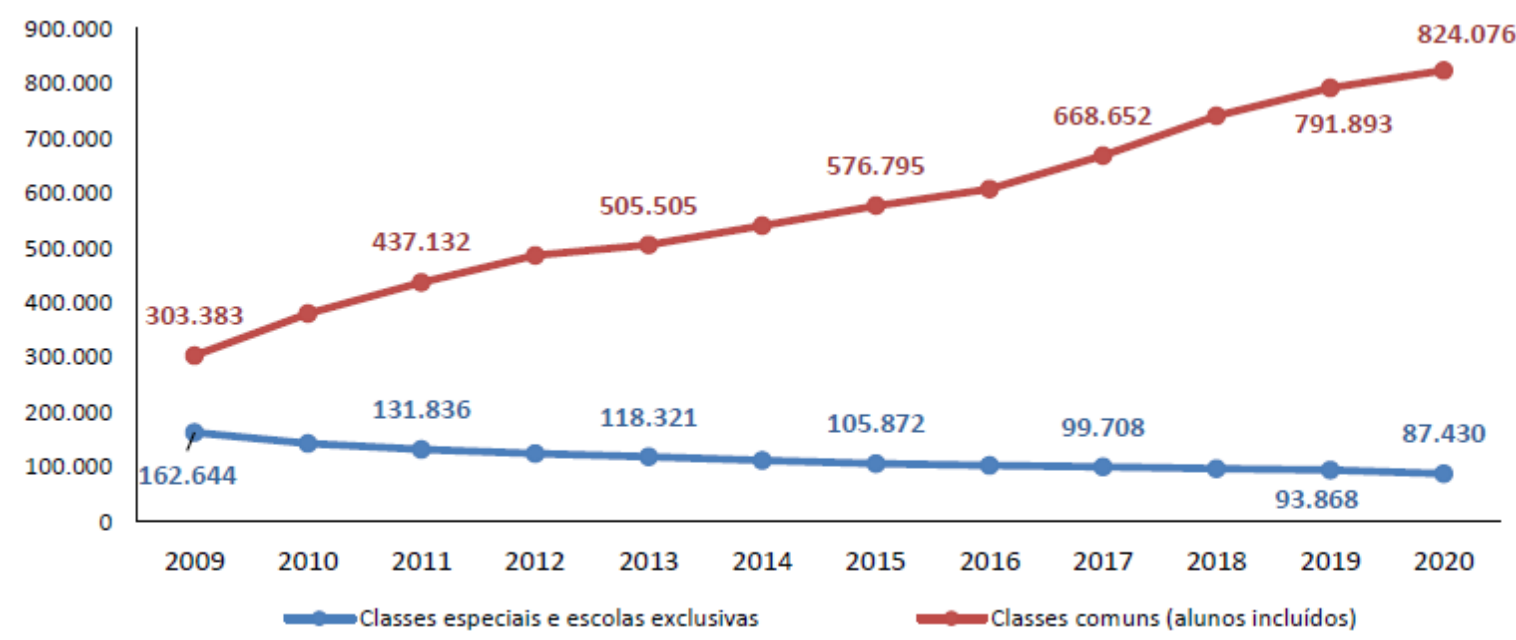

Fonte: Elaborado por Deed/Inep com base nos dados do Censo da Educação Básica 2020 (MEC, 2020).

Figira 3 - Evolução das matrículas de educação especial no ensino médio, por local de atendimento - Brasil 2009 - 2020.

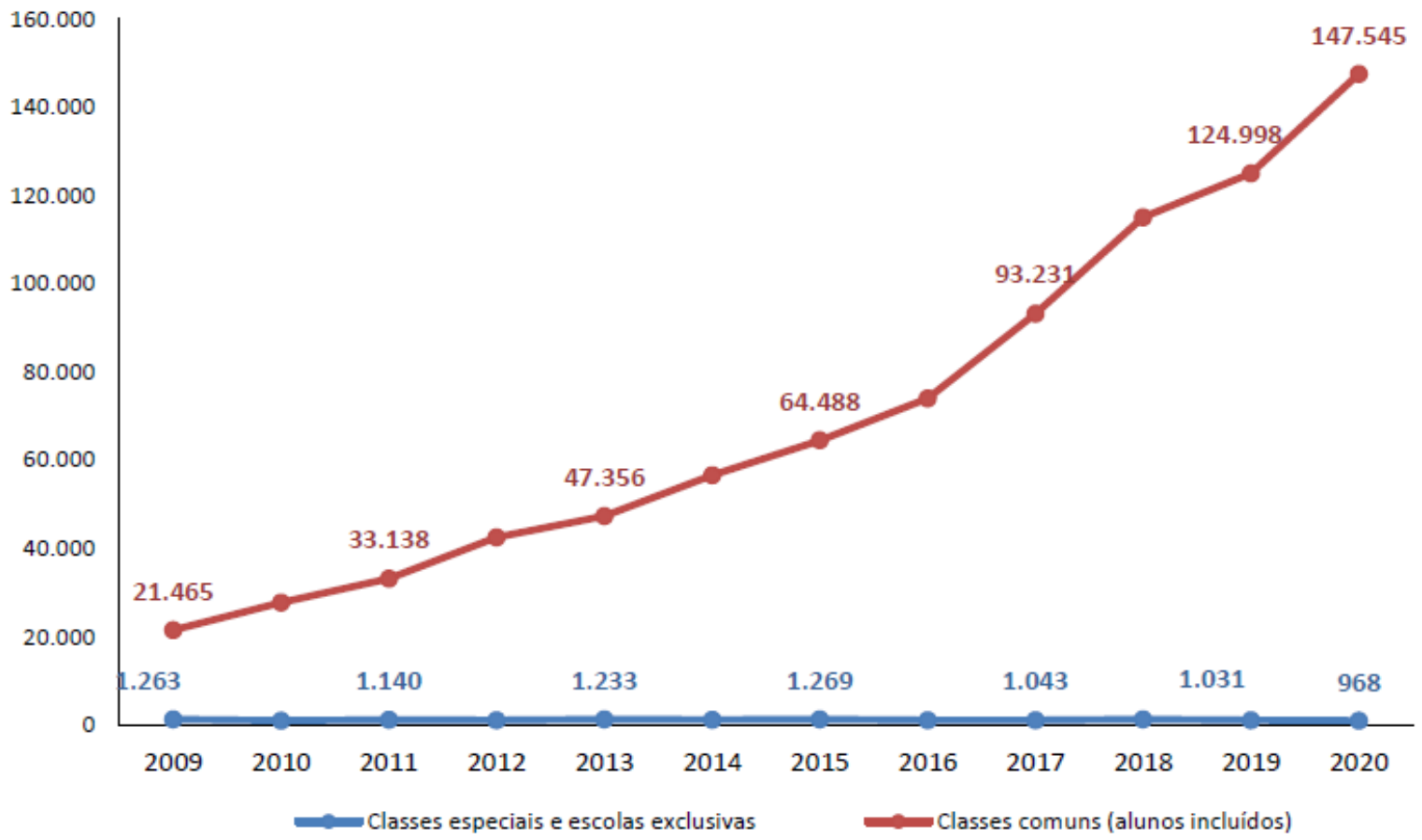

Fonte: Elaborado por Deed/Inep com base nos dados do Censo da Educação Básica 2020 (MEC, 2020). 
Figura 4 - Percentual de alunos de educação especial incluídos (classe comum) por etapa de ensino, segundo a unidade da federação - Brasil 2020.
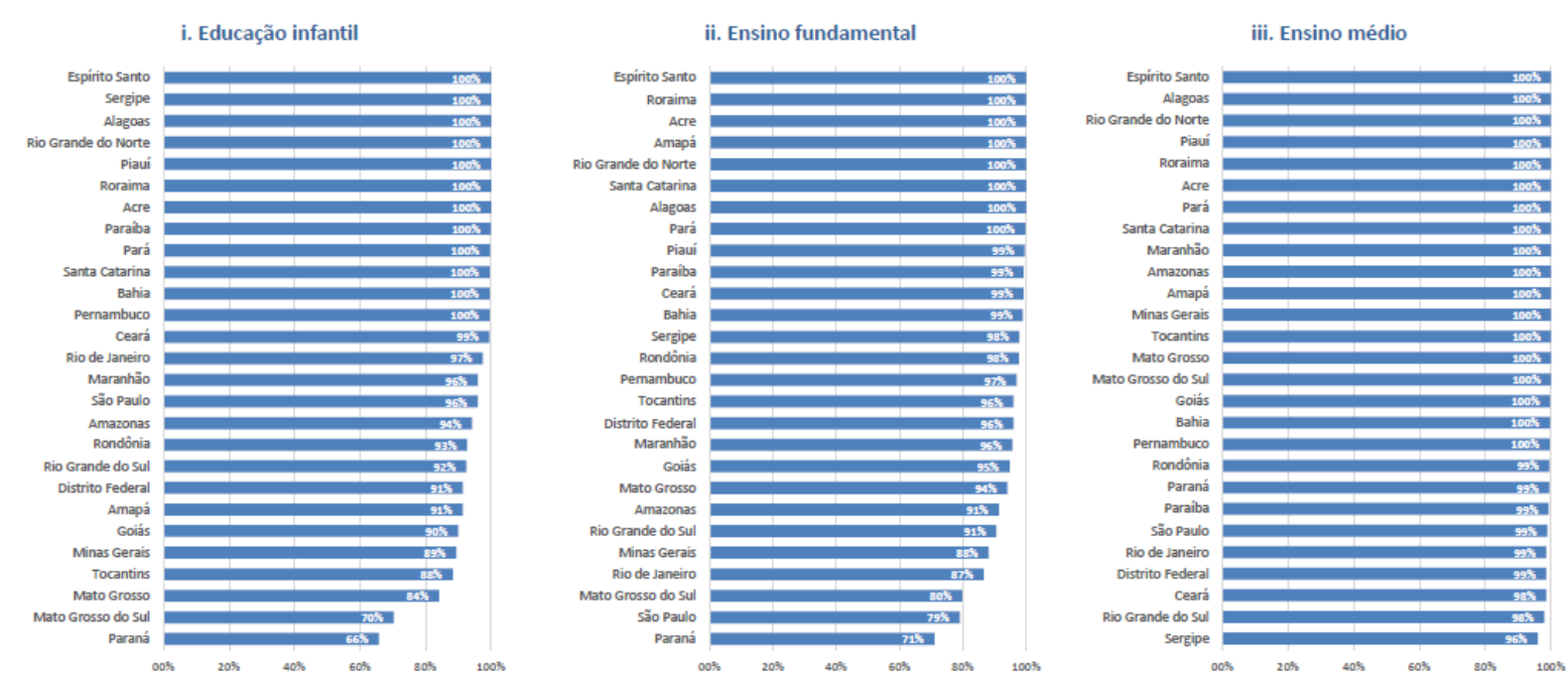

Fonte: Elaborado por Deed/Inep com base nos dados do Censo da Educação Básica 2020 (MEC, 2020).

Figura 5 - Matrícula na educação especial por tipo de deficiência, transtorno global do desenvolvimento ou altas habilidades/superdotação - Brasil 2020.

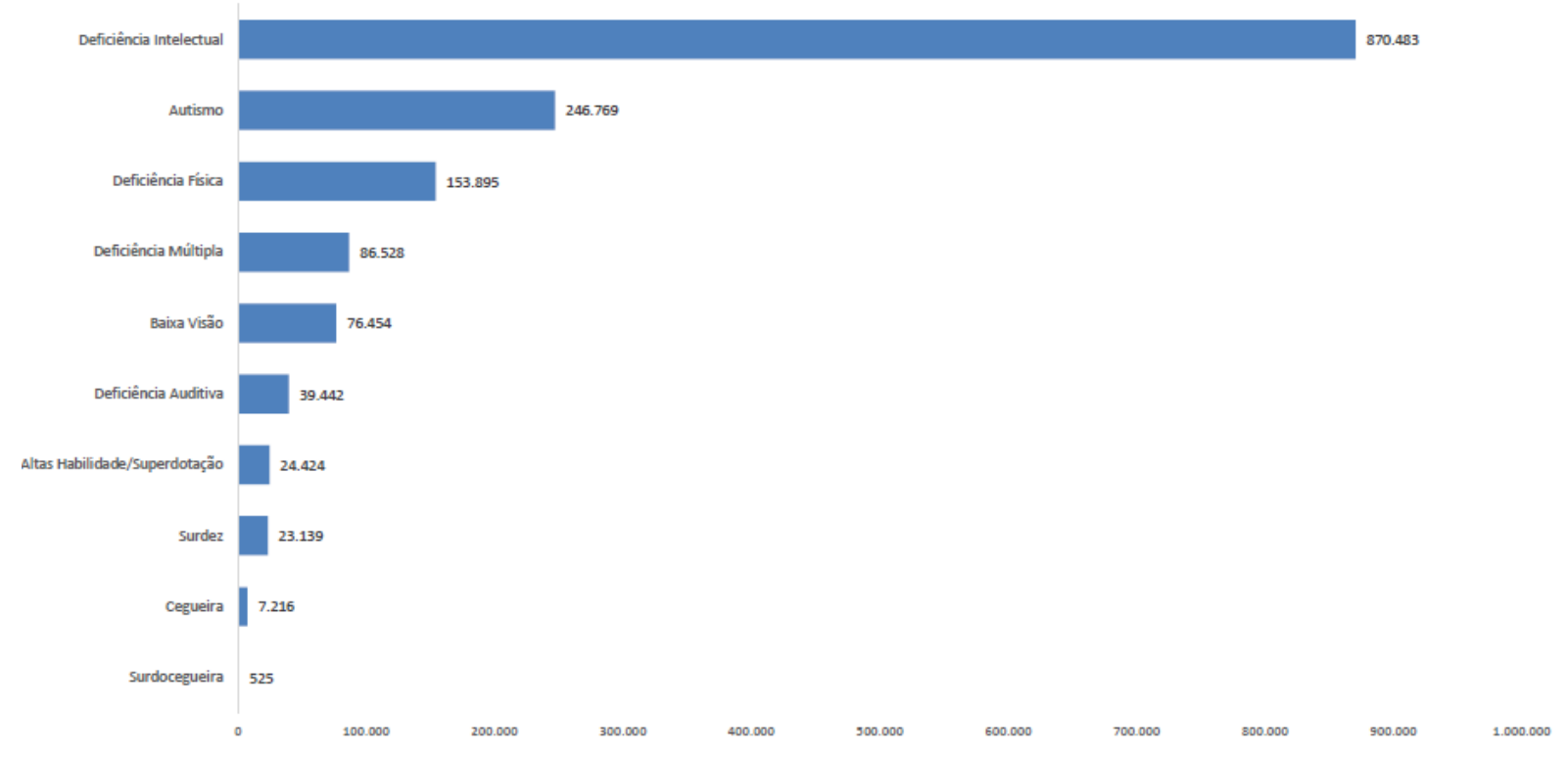

Fonte: Elaborado por Deed/Inep com base nos dados do Censo da Educação Básica 2020 (MEC, 2020).

\section{Discussão}

A Lei n. 9394/96, que estabeleceu as Diretrizes e Bases da Educação Nacional, em seu Artigo 59 determina que os sistemas de ensino assegurarão aos educandos com necessidades especiais, entre outros aspectos: currículos, métodos, técnicas, recursos educativos e organização específicos, para atender às suas necessidades, bem como terminalidade específica para aqueles que não puderem atingir o nível exigido para a conclusão do ensino fundamental, em virtude de suas deficiências. Neste mesmo aparato legal, as categorias de deficiência são diluídas no conceito de necessidades educacionais especiais. O termo é 
utilizado inicialmente na Declaração de Salamanca para caracterizar crianças com deficiência e crianças bem dotadas; crianças que vivem nas ruas e que trabalham; crianças de populações distantes ou nômades; crianças de minorias linguísticas, étnicas ou culturais e crianças de outros grupos ou zonas desfavorecidos ou marginalizados (Conferência Mundial Sobre Necessidades Educacionais Especiais, 1994). Isto indica que a deficiência é entendida como uma expressão localizada da diversidade que compõe as chamadas necessidades educacionais especiais.

Conforme mostrado no presente trabalho, verificou-se um aumento nas matriculas demonstra que as discussões sobre as práticas relacionadas à deficiência estão sendo produtivas e provocando mudanças significativas nos conceitos, nas legislações, nas práticas educacionais e de gestão, dessa forma garantindo a permanecia desses alunos (MEC, 2008). Portanto, é por meio da educação que se podem analisar as atitudes e, dessa forma conseguir modificá-la, conforme Adorno (1967; 1972), “a formação, a diferenciação individual, ocorre através da cultura, pois ao adquiri-la esses conceitos nos permitirá expressar nossos desejos, sofrimentos expectativas". A escola deve trabalhar tendo em vista uma educação inclusiva com oportunidades de aprendizagem para alunos com deficiência, tem-se solicitado sua organização tanto na acessibilidade quanto nas questões curriculares e pedagógicas, considerando que as escolas, em sua maioria, não atendem a essas exigências que buscam a aprendizagem dos alunos com deficiência como ressaltado em estudos de (Costa, 2012).

Com implementação de políticas públicas de educação e formação adequada de professores e, as expectativas para uma educação que proporcione o ingresso dos alunos que apresentam alguma deficiência ao currículo escolar e às classes regulares, utilizando-se de atividades pedagógicas que avaliem suas diferenças de aprendizagem, revelando a urgência por educação democrática, capaz de se constituir como alternativa para que se consiga superar as diferenças de aprendizagem como obstáculo ao acesso e permanência na escola pública, refletir sobre as posturas instauradas nas escolas é uma forma de buscar mudanças significativas nas atitudes das pessoas, principalmente nas envolvidas com o processo educacional dos alunos que apresentam alguma deficiência, só assim, pode-se almejar uma sociedade justa e humana (Costa, 2012, p.89-110).

Portanto a Educação inclusiva visa à integração das pessoas com deficiência nas classes comuns de ensino regular, no entanto, está longe de ser uma doutrina em que há uma imposição de matrícula e permanência de alunos em estruturas escolares que não assegurem as condições necessárias ao aprendizado destas pessoas, como uma boa estrutura física e recursos especiais disponíveis para o aprendizado. Pensando neste sentido, a Educação Inclusiva propõe condições reais para que haja não apenas o acesso, mas a permanência e o êxito de uma educação com qualidade para aqueles que possuem suas diferenças (Mazzotta \& D’Antino, 2012; Garcia\& Favaro, 2020).

Sendo assim, a primeira década do novo milênio é, sem dúvidas, um momento de intensificação das diretrizes que vinculam a ampliação da escolarização dos alunos com deficiência e a valorização do ensino comum no Brasil. Podemos identificar que tais orientações ganharam organicidade com a aprovação da Política Nacional de Educação Especial na Perspectiva da Educação Inclusiva de 2008 (Brasil, 2008). Essa intensificação teve efeitos perceptíveis, em um primeiro plano, nos índices de matrículas dos alunos com deficiência, que passaram progressivamente a estar em maior número nas classes do ensino comum. Esses alunos eram 145.141, em 2003, e somavam 750.983, em 2015, segundo dados do Censo Escolar do Inep. Em modo processual, as matrículas em classes especiais e escolas especiais diminuíram, passando de 358.898 (2003) para 179.700 (2015). Como podemos perceber no gráfico abaixo, a inversão de tendência do fluxo de matrículas ocorreu entre os anos de 2007 e 2008, momento de debate e aprovação da Política Nacional de Educação Especial na Perspectiva da Educação Inclusiva de 2008.

Os autores Rebelo e Amaral (2003, p. 291) afirmam que "o número de matrículas de alunos da Educação Especial aumentou em todas as regiões no período de 2007 a 2014”. Esses índices continuam a mostrar crescimento de matrículas nos anos seguintes. De acordo com o Censo Escolar do INEP de 2017 (Brasil, 2015), ao considerarmos a educação básica, há um predomínio da escolarização em escolas municipais (quase 50\% do total de matrículas), e o percentual de alunos incluídos no 
ensino comum era de 90\%. Podemos, assim, identificar efeitos de uma política educacional que manteve o foco na universalização da educação no país, o que deve ser reconhecido como um aspecto promissor. Entretanto, é importante que sejam analisadas as condições de escolarização, contemplando dimensões como a participação, os apoios e o desempenho escolar.

Portanto, as significativas alterações dos índices educacionais relativos à escolarização das pessoas com deficiência devem ser analisadas a partir de uma mudança de gestão, iniciada com o primeiro governo do Presidente Lula da Silva, em 2003. A meta de inclusão escolar passa a integrar um plano de ação que tendia a buscar que os direitos sociais ganhassem efetividade, envolvendo diferentes grupos que têm um histórico de desvantagem, como ocorre com as pessoas com deficiência (Baptista, 2019).

Em 2008, foi um momento histórico com essas características que emerge o debate que instituiu a Política Nacional de Educação Especial na Perspectiva da Educação Inclusiva como um conjunto de diretrizes que demandariam posteriormente dinâmicas de operacionalização instituídas por meio de programas ministeriais e por dispositivos normativos. Para o debate e a elaboração desse documento de diretrizes foi constituído um grupo de trabalho4 composto por integrantes da então Secretaria de Educação Especial do MEC - SEESP - e consultores convidados em função de experiência acadêmica no trabalho como pesquisadores e formadores na área da educação especial. Estes consultores eram integrantes de Programas de Pós-Graduação em Educação em universidades públicas de diferentes regiões do país. As ações relativas ao trabalho de discussão foram desenvolvidas ao longo de 2007, em reuniões do Grupo de Trabalho e atividades abertas, como reuniões ampliadas com pesquisadores e com representantes de instituições que se ocupavam de temáticas relativas aos direitos das pessoas com deficiência, incluindo as instituições especializadas. Ao longo de 2007, houve muitas audiências públicas em várias capitais brasileiras para a discussão dessas diretrizes, com base inclusive em uma minuta divulgada em setembro daquele ano. Um dos principais espaços de discussão das diretrizes foram seminários envolvendo gestores e professores de redes públicas no âmbito do Programa Educação Inclusiva: Direito à Diversidade,5 com destaque para seminários organizados por macrorregiões, como em Natal-RN e em Florianópolis-SC, ambos no mês de agosto de 2007. O texto final foi publicado em janeiro de 2008, com a apresentação do então Ministro da Educação - Fernando Haddad - na Revista Inclusão. O texto da Política Nacional de Educação Especial na Perspectiva da Educação Inclusiva de 2008 indica como objetivo:

[...] assegurar a inclusão escolar de alunos com deficiência, transtornos globais do desenvolvimento e altas habilidades/superdotação, orientando os sistemas de ensino para garantir: acesso ao ensino regular, com participação, aprendizagem e continuidade nos níveis mais elevados do ensino; transversalidade da modalidade de educação especial desde a educação infantil até a educação superior; oferta do atendimento educacional especializado; formação de professores para o atendimento educacional especializado e demais profissionais da educação [...] e articulação intersetorial na implementação das políticas públicas. (Brasil, 2008, grifos meus).

A educação comum como diretriz soma-se à afirmação da transversalidade da educação especial, já destacada na LDB de 1996. O mais importante, segundo meu ponto de vista: deixa-se de referir condições de exceção ao processo de inclusão esse é um elemento de novidade em termos de diretrizes. No que concerne ao alunado, após um longo debate acerca das vantagens e dos riscos de um conceito amplo como necessidades educativas ou educacionais especiais, que marcou a educação especial brasileira no início dos anos 2000, a política define um grupo mais específico de sujeitos, resgatando a tríade já enfatizada pela Política Nacional de Educação Especial de 1994: pessoas com deficiências, transtornos globais de desenvolvimento e altas habilidades.

Sendo assim, fica evidente que houve alterações nas diretrizes para a educação especial, porém eram imprescindíveis iniciativas que estivessem em sintonia com tais metas e que contemplassem investimentos na construção de dispositivos propulsores de efeitos mais pragmáticos. Tais iniciativas envolveram duas dimensões prioritárias: o plano normativo e aquele da gestão dos sistemas de ensino. No que se refere ao primeiro, houve a aprovação de dispositivos que passaram a indicar a 
obrigatoriedade de oferta do apoio especializado, como a Resolução nº 04/2009 do CNE (Brasil, 2009), e que asseguravam o direito de acesso à escola comum para os alunos com deficiência, como o Decreto no 6949/2009 (Brasil, 2009), o qual tem efeitos de emenda constitucional.

Para ter uma mudança na gestão dos sistemas, foi intensificada uma rede de programas ministeriais, na forma de um conjunto articulado, envolvendo a formação continuada de professores, a assistência social, a acessibilidade, o acesso ao ensino superior e a implementação de serviços de apoio. Esses programas são destacados por, quando analisam o plano de gestão da política relativa à educação especial. Dentre esses programas ministeriais, destaco dois que passaram a ter importância estrutural na gestão, pois envolviam a formação e sensibilização - Programa Educação Inclusiva: Direito à Diversidade - e a implementação dos apoios que passavam a ter uma dimensão prioritária - Programa de Implantação de Salas de Recursos Multifuncionais ( Baptista, 2019).

Com foco em diferentes regiões do país, têm destacado o critério de acesso à escola e o predomínio das matrículas dos alunos com deficiência no ensino comum, onde destacou as singularidades e os desafios presentes em diferentes planos da ação específica desenvolvida pelos gestores locais, com ênfase na tendência de concentração de matrículas nos anos iniciais da escolarização e na oferta insuficiente do atendimento educacional especializado, apesar da grande elevação numérica das salas de recursos. São ainda evocados fenômenos como a rotatividade de profissionais em função de diferentes formas de contratação por parte dos sistemas de ensino (Rebelo \& Amaral, 2003).

Portanto, identificamos que houve, entre 2007 e 2009 e continuou até 2020, a intensificação da inclusão como meta, com o apoio de programas ministeriais que já existiam e com o debate relativo às diretrizes que passariam a reger a política brasileira sobre a escolarização das pessoas com deficiência. Trata-se de uma perspectiva muito diferente da designada integração instrucional relativa aos anos 1900. Esse momento histórico é também aquele de aprovação da Convenção sobre os Direitos das Pessoas com Deficiência - ONU/2006 -, que passa a integrar o ordenamento jurídico brasileiro, com status constitucional, definindo que "o direito da pessoa com deficiência à educação se efetiva somente em um sistema educacional inclusivo, em todos os níveis, etapas e modalidades" (Brasil, 2013).

\section{Considerações Finais}

No estudo foi possível identificar um movimento progressivo da educação especial brasileira no sentido da escolarização como direito, integrando uma política pública que se mostra em modo recente e posterior aos anos 1970 - um processo oscilante e marcado por rupturas e por continuidades. Embora o foco inicial fosse o cenário dos últimos dez anos, houve uma opção de resgate histórico para operar por contraste entre as metas, os atores sociais e as palavras que marcaram a educação especial brasileira como iniciativa de política pública em diferentes décadas.

Nos anos de 2009 até 2020, as matriculas de alunos especiais em classe comum seguiu uma reta crescente na educação básica, no ensino fundamental e médio. Esse crescimento está relacionado a implementação de políticas públicas de educação e formação adequada de professores. Estes dados mostra a importância de uma política pública séria que luta pela inclusão dos alunos com algum tipo de deficiência sejam colocados dentro de uma classe comum. Entretanto, precisa-se quebrar alguns tabus para que os alunos com deficiência tenham mais presença nas escolas, esses tabus muita das vezes tem que ser quebrado dentro de casa pelos pais, as vezes os pais tem medo de expor seus filhos, como medo de sofrem discriminação por parte da sociedade.

\section{Referências}

Adorno, T. W. (1967). Educação após Auschwitz. In: Educação e emancipação. Rio de Janiero: Paz e Terra.

Baptista, C. R. (2019). Política pública, Educação Especial e escolarização no Brasil. Educ. Pesqui., São Paulo, v. 45 , e217423.

Brasil (1988). Constituição (1988). Constituição da República Federativa do Brasil. Brasília, D.F:Senado, 1988. 
Research, Society and Development, v. 11, n. 1, e23811124794, 2022

(CC BY 4.0) | ISSN 2525-3409 | DOI: http://dx.doi.org/10.33448/rsd-v11i1.24794

Brasil (1994). Declaração de Salamanca e linha de ação: sobre necessidades educativas especiais. Brasília: CORDE, 1994.

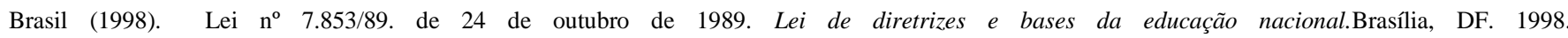
http://www.rebidia.org.br/seesp/dadps.html. Acesso em: 20 fev. 2005>.

Brasil (1996). Lei $\mathrm{n}^{\circ}$ 9.394/96. de 20 de dezembro de 1996. Lei de diretrizes e bases da educação nacional. Brasília, DF: SEE, 1996. http://www.rebidia.org.br/seesp/ dadps.html.

Brasil (1996). Lei n. 9394, de 20 de dezembro de 1996, que estabelece as Diretrizes e Bases da Educação Nacional. Brasília: MEC.

Brasil. (2012). Ministério da Educação. Instituto Nacional de Estudos e Pesquisas Educacionais Anísio Teixeira (INEP). Censo Escolar da Educação Básica 2012. Brasília, DF: MEC/Inep. <http://www.inep. gov.br/basica/levantamentos/microdados.asp>.

Brasil. (2015). Ministério da Educação. Nota técnica Conjunta n n 02/2015/MEC/SECADI - SEB/DICEI. Orientações para organização e oferta do atendimento educacional especializado na educação infantil. Brasília: Brasília: Secretaria de Educação Especial.

Brasil. (2008). Ministério da Educação. Secretaria de Educação Especial. Política Nacional da Educação Especial na perspectiva da Educação Inclusiva. Brasília: MEC/SEESP, 2008. <http://portal.mec.gov.br/ seesp/arquivos/pdf/politica.pdf>.

Caiado, K. R. M. (1993). Concepções sobre deficiência mental reveladas por alunos concluintes do curso de pedagogia deficiência mental. Dissertação de Mestrado. Universidade Federal de São Carlos-SP.

Costa, V.A. (2012) . Formação de professores e educação inclusiva frente às demandas humanas e sociais: para quê. O Professor e a educação inclusiva: formação, práticas e lugares. Salvador: EDUFBA, p. 89-110.

Educacionais Anísio Teixeira (INEP). Censo Escolar da Educação Básica - 2009. Brasília, DF: MEC/Inep, 2009. <http:// www.inep.gov.br/basica/ levantamentos/microdados.asp.

Ferreira, J. R. (1992). Notas sobre a evolução dos serviços de educação especial no Brasil. Revista Brasileira de Educação Especial, Piracicaba: Unimep, v.1, n.1, p.101-106.

Garcia, D.I.B.; Favaro, N.A.L.G. (2020). Educação Especial: políticas públicas no Brasil e tendências em curso. Research, Society and Development, v. 9, n.7, e184973894.

Gil, A. C. (2008). Como elaborar projetos de pesquisa. $4^{\mathrm{a}}$ edição. São Paulo. Atlas.

Gotti, M. O. (1998). Integração e Inclusão: nova perspectiva sobre a prática da educação especial. In: MARQUEZINE, M. C. et al. (Org.). Perspectivas multidisciplinares em educação especial. Londrina: Ed. UEL, p. 365 - 372.

Leonardo, N. S. T.; Bray, C. T.; Rossato, S. P. M. (2009). Inclusão Escolar: Um Estudo Acerca da Implantação da Proposta em Escolas de Ensino Básico. Rev. Bras. Ed. Esp., Marília, v.15, n.2, p.289-306.

Mazzotta, M. J. S.; D'Antino, M. E. F. (2011). Inclusão social de pessoas com deficiências e necessidades especiais: cultura, educação e lazer. Saúde Soc., São Paulo, v. 20, n. 2, p. 377-389.

Mendes, E. G. (2008). Inclusão escolar com colaboração: unindo conhecimento, perspectivas e habilidades profissionais. In: Martins, L. A. R. et al. Políticas e práticas educacionais inclusivas. Natal: EDUFRN.

Ministério da Educação. Secretaria de Educação Especial. (2008). Política Nacional de Educação Especial na Perspectiva da Educação Inclusiva. Brasília: MEC/SEESP.

Penha, A.C.F.M.; Fecury, A.A.; Pascoal, R.M.; Dendasck, C.V.; Araújo, M.H.M.; Souza, K.O.; Silva, I.R.; Moreira, E.C.M; Moraes, J.S.; Oliveira, E.; Dias, C.AG.M. (2020). Matrículas da Educação Especial na Educação Profissional Técnica de Nível Médio no Estado do Amapá (2015-2018). Research, Society and Development, v. 9, n.7, e881974867.

Rabelo, A. S.; Amaral, I. J. L. (2003). A formação do professor para a inclusão escolar: questões curriculares do curso de Pedagogia. In: Lisita, V. M. S. S.; Sousa, L. F. E. C. P. (Orgs.) Políticas educacionais, práticas escolares e alternativas de inclusão escolar. Rio de Janeiro: DP\&A.

Santos, G.C.S. (2002). Diversidade e educação: desafios à formação e à atuação docentes. In: Magalhães, R. C. P. Reflexões sobre a diferença: uma introdução à educação especial. Fortaleza: Edições Demócrito Rocha.

Vigotski, L.S. (1997). Obras escogidas V: Fundamentos de defectología. Madrid: Visor Distribuciones. 